\title{
Host food preference, screening and phylogenetic analysis of Wolbachia in Myzus persicae populations
}

\author{
Bilal Rasool ${ }^{1}$, Zeeshan Nabi ${ }^{1}$, Muhammad Adnan Bodlah ${ }^{2}$, Naveed Afzal1 ${ }^{1}$, Khizer Samiullah ${ }^{1}$, Awais Rasool ${ }^{3}$, \\ Rizwan Rasool ${ }^{1}$ \\ ${ }^{1}$ Departement of Zoology, Faculty of Life Sciences, Government College University, Faisalabad, Pakistan \\ ${ }^{2}$ Fareed Biodiversity Conservation Centre, Department of Agricultural Engineering, Khawaja Fareed University of \\ Engineering and Information Technology, Rahim Yar Khan, Pakistan \\ ${ }^{3}$ Integrated Pest Management Programme, National Agriculture Research Centre (NARC), Islamabad, Pakistan
}

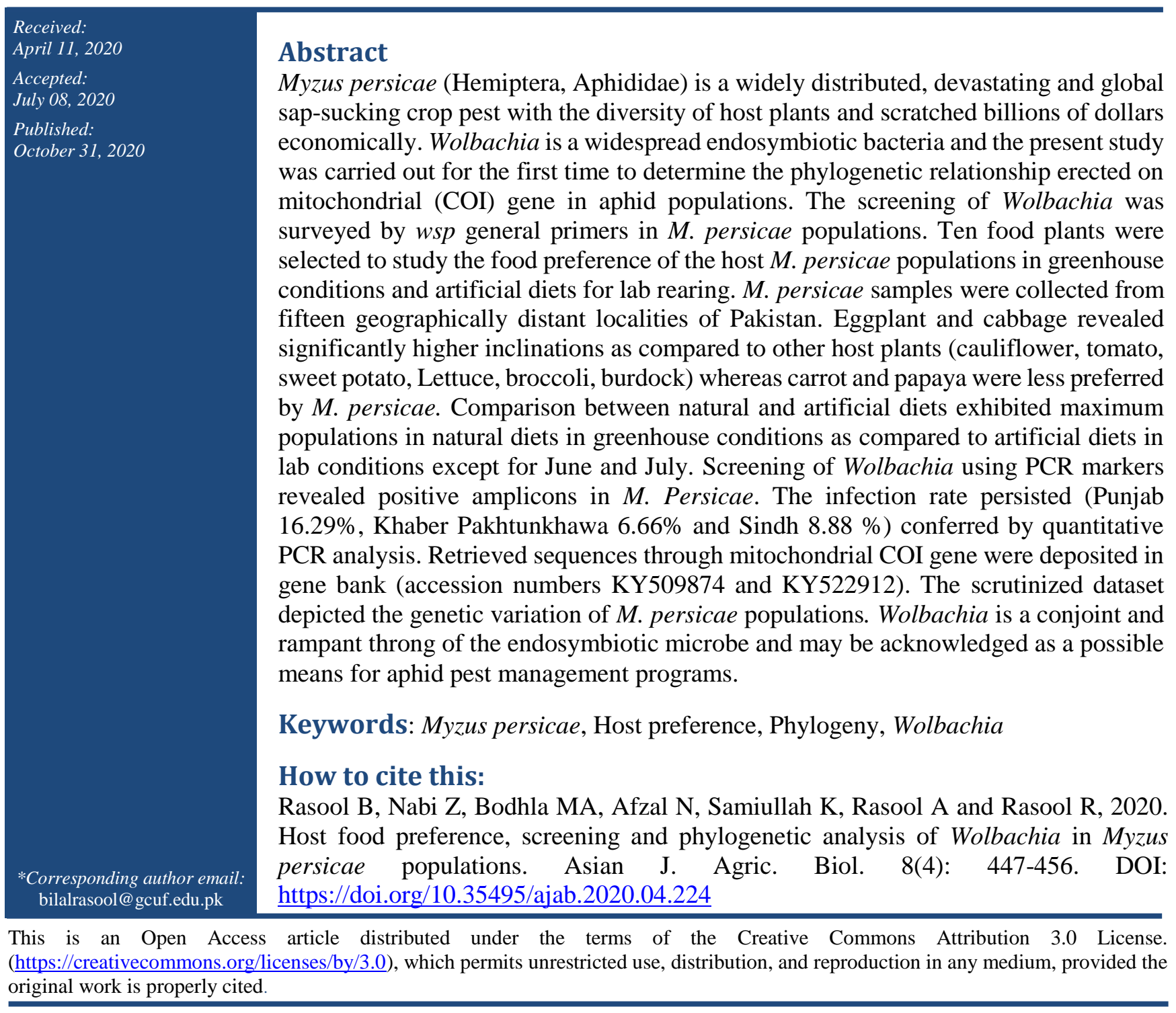




\section{Introduction}

Myzus persicae, aphids are grubby pests of agriculture globally owing to their aptitude for the efficacious aerial diaspora. Aphids encompass more than 4700 species in 600 genera (Loxdale et al., 1993; Van Emden, 2017; Blackman and Eastop, 2018) and due to their feeding demeanor, these are the most vivacious plant virus trajectories, transmitting about $30 \%$ among entire plant virus sorts (Brault et al., 2010). These explicate hurriedly emerging organisms with high levels of discrepancy and differ in their host preference (Loxdale and Lushai, 2007; Loxdale et al., $1993 \&$ 2017). These host rivalries demonstrate diverse echelons of multiplicative seclusion resulting in local adaptation and further intimation to an inchoate speciation progression (Ferrari et al., 2008) Myzus persicae colonizes an immense diversity of environments due to its cosmopolitan nature and has great economic importance among all aphid species (Bass et al., 2014). The cosmopolitan distribution includes, wide host diversity, apparatuses of plant impairment, life progression, the aptitude to scatter are some factors that enhance the pest eminence of these species. $M$. persicae is successful cosmopolitan species with polyphagia nature and with over 400 host sorts in 40 diversified plant families comprising various parsimoniously significant crop floras (Blackman and Eastop, 2018). Molecular indicators usages in the phylogenetic edifications of several organisms have settled progressively essential in contemporary eras. A well-known protein cytochrome oxidase is instigated in both microbe and mitochondria. Both genes CO I and II have been used to elucidate phylogenetic glitches at an eclectic array of hierarchical echelons among insects and applauded through a probable barcode for entomological identification (Patwardhan et al., 2014). The mitochondrial (mt) genome has had an enormous impact on the genetics studies of entomological genetics and primarily, mt genes were extensively used due to the limitations of alternatives across insects (Caterino et al., 2000). Recently the emphasis of the DNA-barcoding community on the mitochondrial- cytochrome oxidase subunit 1 (CO1) as a near-exclusive data foundation for species documentation and demarcation (Hebert et al., 2002) has additionally improved the frequency of mitochondrial sequencing.

Wolbachia is a maternally transmitted endosymbiont belonging to the $\alpha$-proteobacterium (Werren et al.,
2008; Hilgenboecker et al., 2008). These microbes are possibly the most conjoint intracellular symbiont in the atmosphere, tainting an appraised $25-75 \%$ of the entomological sorts (Hilgenboecker et al., 2008; Jeyaprakash and Hoy, 2000). Wolbachia behaves more often like a reproductive parasite (Werren et al., 2008) and mainly resides in the multiplicative layers of the host causing a variety of reproductive amendments (Werren et al., 2008) for instance malekilling, feminization, Parthenogenesis, and Irreconcilability of the cytoplasm in different entomological species (Dyer and Jaenike, 2004; Vandekerckhove et al., 2003; Stouthamer et al., 1999; Poinsot et al., 2003).

Insufficient studies have been scrutinized aimed at the characterization of these endosymbionts in aphids (Jeyaprakash and Hoy, 2000; Gómez-Valero et al., 2004) and most of these studies remained abortive to detect (Nirgianaki et al., 2003; Werren et al., 2008). The major report of aphids harboring these microbes was PCR amplification of wsp gene (Jeyaprakash and Hoy, 2000) though not included Myzus species. Sturdier substantiation in Cinara cedri aimed at the occurrence of these microbes in aphid sorts existed on gene 16S rDNA (Gómez-Valero et al., 2004). It was described that wheat aphid, Sitobion miscanthi, from China anchorage these endosymbionts contagions fit in super group cataloging of A and B (Wang et al., 2014). During the study, we commenced extensive screening of the occurrence of endosymbiont contagions in $M$. persicae populaces, phylogenetics and food preference of the host involved. We performed comprehensive screening, sequencing of the mitochondrial COI gene and $w s p$ amplification for evaluation.

\section{Material and Methods}

\section{Sample collection}

Myzus persicae (Sulzer) were captured through installing yellow pan traps, hand, aerial sweep nets, sticky bands, aspirators and tip sampling techniques from different locations (Table 3) of the provinces of Pakistan over $1500 \mathrm{~km}$ climate gradients. Twenty-five traps were installed at different places for each locality with regular monitoring of each trap after 24 hours. These live collected samples were brought in the insect rearing lab of Government College University Faisalabad for $M$. persicae colonies. The samples were collected from 15 geographically distant areas during the years (2015-2018) mentioned in table 3 
within Pakistan to have a deeper insight into the genetic diversification. Monitoring was also performed to calculate the total population of wingless aphids in the selected fields. $10-15$ plants were selected in each of three experimental fields per locality and mean populations were calculated correspondingly. The $M$. persicae samples were preserved in $90 \%$ ethanol and a part of the aphid population was kept alive for subsequent rearing in the lab and semi-field conditions (greenhouse). Samples were collected from May to August during the years (2015-2018), for instance, there is the distinguished summer season and restrained utmost appropriate months aimed at the prevalence findings of aphids in Pakistan (Hamed, 1983)

\section{Rearing of green peach aphid}

Myzus persicae (Sulzer) population was cherished in greenhouse circumstances on natural food and synthetic diet in lab to compare the effects of diets on the insect. Cabbage (Brassica capitata), green cauliflower (Brassica oleracea var. Botrytis), tomato (Solanum lycopersicum), sweet potato (Ipomoea batatas), broccoli (Brassica oleracea var. Italica), papaya (Carica papaya), lettuce (Lactuca sativa), carrot (Daucus carota), burdock (Arctium L.) and eggplants (Solanum melongena) were used as natural diets for the rearing of the aphids in the greenhouse. These plants were planted in the commercially available plastic pots of size $(26 \times 26 \times 20 \mathrm{~cm})$ and all these plants were placed in specially designed perspex cages $(50 \times 50 \times 40 \mathrm{~cm})$. Air entered the cages through an opening covered with minute mesh used to avoid insects evading during rearing for the accuracy of the results. Synthetic diet (Dadd et al., 1967) was formulated using sucrose $1500 \mathrm{mg}$, dipotassium hydrogen, orthophosphate $750 \mathrm{mg}$, Magnesium sulfate $123 \mathrm{mg}, \mathrm{L}$ - glutamine $150 \mathrm{mg}$, L- tyrosine 40 $\mathrm{mg}$. $\mathrm{L}$ - alanine $100 \mathrm{mg}, \mathrm{L}-$ aspartic acid $140 \mathrm{mg}, \mathrm{L}$ - glutamic acid $150 \mathrm{mg}, \mathrm{L}$ - glycine $80 \mathrm{mg}$, vitamin C $100 \mathrm{mg}$, vitamin B2 $0.5 \mathrm{mg}$, vitamin B9 $0.5 \mathrm{mg}$, Pyridoxine hydrochloride $2.0 \mathrm{mg}$ and vitamin B310 mg with different modifications and most suitable standardized diet was operated in the lab. 550 samples of Myzus persicae were released for both diet categories and live samples were calculated for the estimation of relative growth rate separately. Population dynamics were counted for each month separately every week. The experiments were replicated ten times (five of each natural and artificial diets) during the years (2015-2018). During the lab experiments, $M$. persicae population was recorded for each month on weekly basis in the controlled environment $\left(25 \pm 1{ }^{\circ} \mathrm{C}, 70 \pm 5 \% \mathrm{RH}, \mathrm{L} 15\right.$ : D09) whereas for the greenhouse experiments the population was recorded from the whole plant under natural environmental conditions.

\section{PCR and qPCR analysis with mitochondrial and wsp markers}

DNA extraction was accomplished from field populations through Thermo Fisher Scientific, Pure Link Genomic DNA Mini Kit K182001 extraction kit by ensuing the manufacturer's standard etiquette and DNA was stored at $4{ }^{\circ} \mathrm{C}$ for the subsequent analysis. Mitochondrial COI gene was coxswained to study the barcoding and phylogenetics of aphid samples using PCR with Pat (5'-tccaatgcactaatctgccatatta-3') and Dick (5'-ccaacaggaattaaattttagagattagc-3') (Simon et al., 1994). Total 150 samples 10 from every 15 localities (9 in Punjab, 3 in Khyber Paktun-Khawa and 3 in Sindh) were examined for the amplification of the mitochondrial CO I gene. The gene wsp was amplified with $81 \mathrm{~F}$ (5'tggtccaataagtgatgaagaaac-3') and 691R (5'-aaaaattaaacgctactcca-3') primers to scrutinize Wolbachia infestation (Braig et al., 1998). A total of 225 samples 15 from every 15 localities were scrutinized for wsp gene amplification. PCR master mix kit (Bio-Rad) was used by ensuing the manufacturer's standard procedure. DNA band patterns were visualized on a UV transilluminator geared on gel documentation scheme by running buffer having $1 \mathrm{x}$ TAE and further agars gel concentration (1 to $2 \%$ ) appended with ethidium bromide $(0.51 \mu \mathrm{g} / \mathrm{ml}$.) furthermore the qPCR analysis was performed using Step-One Real-time PCR system manufactured Applied Biosystems through the protocol standardized by (Yang et al., 2014) was followed and curves were confirmed after PCR and purification of the samples.

\section{Statistical analysis}

The datasets of the host preference of Myzus persicae populations for the parameters, 1) comparison of natural and artificial diets, 2) Population density influence of $M$. persicae on the different host plants were endangered to analysis through the Statistics package two way (ANOVA). The mean values were estimated by the Post Hoc Tukey's range test at $\mathrm{P}=$ 0.05 likelihood level. 


\section{Sequence data analysis}

Spawned arrangements of Mitochondrial COI gene were connected by ClustalW software (Thompson et al., 1994) and restraint locations were combed by software Gene Runner 6.5. The categorization datasets were equated by the available mt. sequences from gene bank (Altschul et al., 1997). Ten M. persicae and twenty mitochondrial COI sequences of different aphid species were salvaged from the NCBI repository for phylogenetic study to compare the evolutionary analysis. The assessment of evolutionary deviation amid arrangements, pairwise analysis of eleven sequences of Myzus persicae was steered through the scheme of Maximum Composite Likelihood in the same software. The customary statistics counting the hypervariable sections were scrutinized by the Neighbor-joining (NJ) enactment of MEGA software ensuing Kimura's two-parameter distances (Kumar et al., 2001). Tree topology was established by minimum evolution and maximum parsimony analysis built-in 500 replicates bootstrap values.

\section{Results}

Populations rearing of aphid were carried out together in the laboratory (artificial diets) and in greenhouse circumstances (natural diets) to evaluate the influence of insect density and population dynamics on different diets and natural host plants. Overall mean results exhibited that the maximum population growth was recorded on natural in greenhouse conditions as compared to artificial diets in lab conditions. The maximum population growth rate was observed in May and August in greenhouse conditions whereas in June and July on artificial diets in lab conditions (Fig. 1 a, F-values, 3,32=6.45, P-value 0.002).

The host preference means datasets exhibited significant results for eggplant and cabbage as compared to other host plants (cauliflower, tomato, sweet potato, Lettuce, broccoli, burdock) though lettuce and broccoli are also very close to the cabbage in host partiality whereas carrot and papaya were less preferred by $M$. persicae (Fig. 1 b). However, the overall mean population of $M$. persicae remained highest in August followed by May, July and June whereas the trend remained unchanged during all the studied years (Table 1, months F-values 3, 27= 20.342, P-value 0.000: Host plants F-values 9, $27=$ 18.460, P-value 0.000).

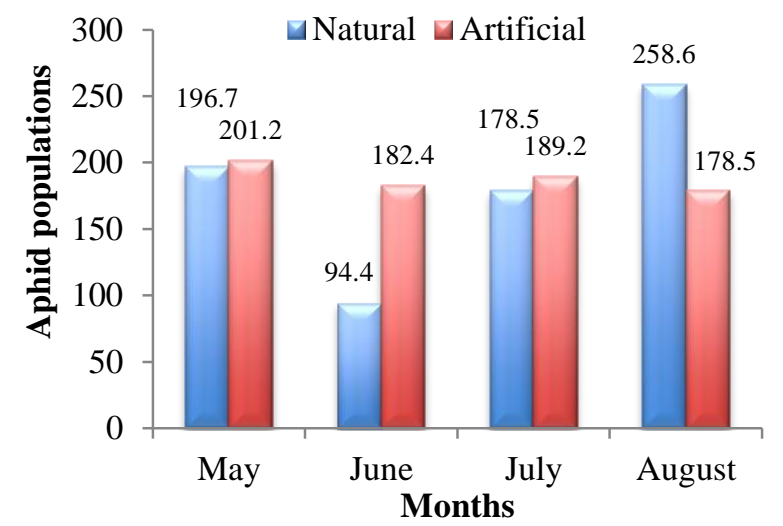

Figure-1a. Mean month wise populations of $M$. persicae on natural (green house) and artificial diet (lab conditions) during the years $(2015-2018)$

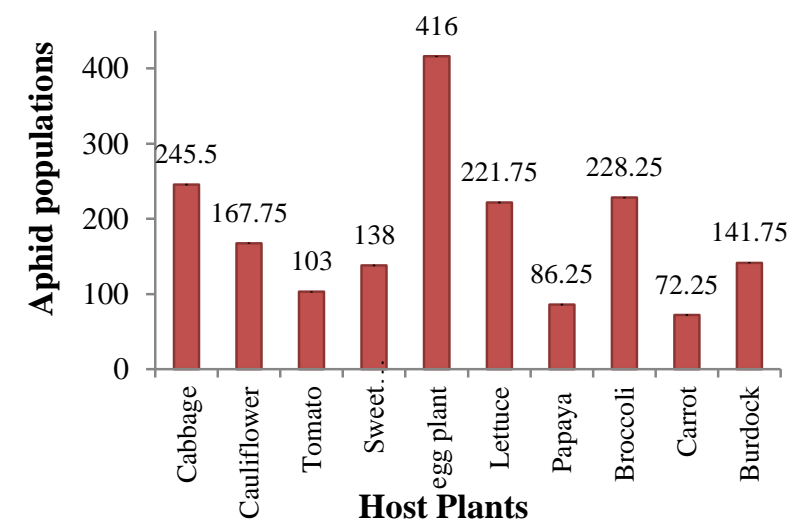

Figure-1b. Mean populations of $M$. persicae on ten different host plants during the years (2015-2018)

Table-1. Means of month-wise populations of Myzus persicae in host plants

\begin{tabular}{|c|c|c|c|c|c|c|c|c|c|c|c|}
\hline \multicolumn{10}{|c|}{ Host Plants } \\
\hline & Cabbage & Cauliflower & Tomato & S. potato & Eggplant & Lettuce & Papaya & Broccoli & Carrot & Burdock & Mean \pm SD \\
\hline May & 342 & 150 & 85 & 110 & 525 & 218 & 97 & 252 & 75 & 113 & $196.7 \mathrm{~b} \pm 143.88$ \\
\hline June & 138 & 87 & 69 & 87 & 199 & 101 & 39 & 116 & 21 & 87 & $94.4 \mathrm{c} \pm 50.13$ \\
\hline July & 185 & 152 & 106 & 155 & 414 & 229 & 75 & 235 & 78 & 156 & $178.5 \mathrm{~b} \pm 99.48$ \\
\hline August & 317 & 282 & 152 & 200 & 526 & 339 & 134 & 310 & 115 & 211 & $258.6 \mathrm{a} \pm 123.72$ \\
\hline Mean & $245.5 \mathrm{~b}$ & $167.75 \mathrm{bc}$ & $103 \mathrm{~d}$ & $138 \mathrm{c}$ & $416 \mathrm{a}$ & $221.75 \mathrm{~b}$ & $86.25 \mathrm{de}$ & $228.25 \mathrm{~b}$ & $72.25 \mathrm{e}$ & $141.75 \mathrm{c}$ & \\
\pm SD & \pm 99.39 & \pm 81.92 & \pm 36.00 & \pm 50.05 & \pm 153.91 & \pm 97.28 & \pm 39.81 & \pm 81.43 & \pm 38.70 & \pm 54.23 & \\
\hline
\end{tabular}

Means sharing similar letter in a row or in a column are statistically non-significant $(\mathrm{P}>0.05), \mathrm{n}=550, \mathrm{SD}=\mathrm{Standard}$ deviation 
Screening of $M$. persicae populations with mitochondrial COI gene

A total of 150 samples from 15 different localities was amplified and 123 positive amplicons were found. Samples from nine localities of Punjab with an average of $79 / 90$ (87.77\%), three from KPK 22/30 (73.33\%) and three from Sindh 23/30 (76.66\%) were found positive for mitochondrial detection (Table 3). The mitochondrial gene COI was successfully amplified approximately 768-771 bps, compared with the complete mitochondrial genome of $M$. persicae 1 to 17382 bps and position found 768 bp (2089 to 2856) and 771bp (2089 to 2859). All the sequences from the COI gene were deposited in Gen-Bank (Accession No KY509874 and KY522912). Tree topologies constructed from the the analysed sequences exhibited two different clusters/subgroups.

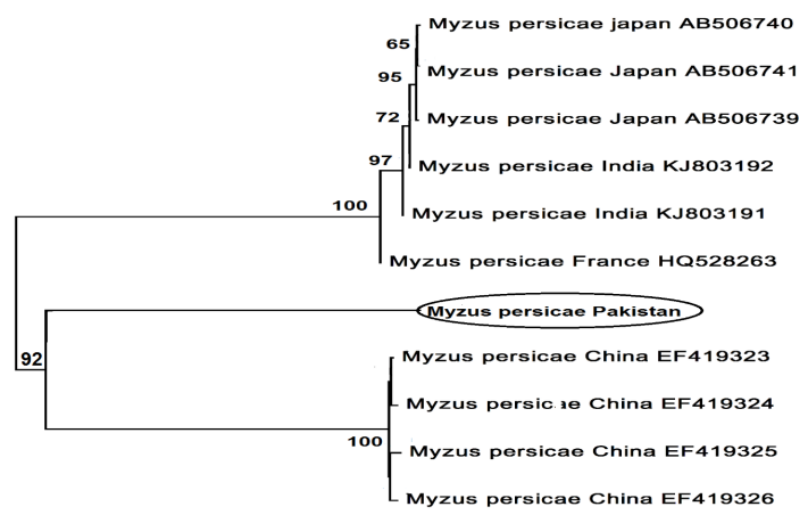

$\lcm{0.05}$

Figure-2a. Eleven sequences (scientific name, country of origin and accession numbers) showing the evolutionary history of aphid populations by the $\mathrm{NJ}$ method and replicate percentage taxa clustered in the bootstrap test (500 replicates) shown to the subsequent outlets, sum of branch length $(\mathrm{SBL})=\mathbf{0 . 5 6 8 5 4 0 0 0}$

China populations of $M$. persicae situated in the first cluster whereas Japan, India, and France populations of $M$. persicae placed in the other cluster. The COI sequences of the $M$. persicae displayed an average $92 \%$ intraspecific similarity with closely related Chinese M. persicae (Fig. 2a). The phylogenetic analysis reveals clearly that Pakistani $M$. persicae is diverse from $M$. persicae instigating from other countries (Fig. 2b), however, the significance is supporting monophyletic and thus a common ancestor. When the Pakistani $M$. persicae sequences were combined and compared further with the sequences from some other aphid species of different countries monophyletic groups were observed for the species of $M$. persicae from china and Pakistan while with other aphid species, $M$. persicae forming a paraphyletic group (Fig. 2b). The codon density comparison of two Pakistani $M$. persicae sequences along with ten other analyzed sequences and the pairwise analysis publicized variation in inters population status showed in Table 2.

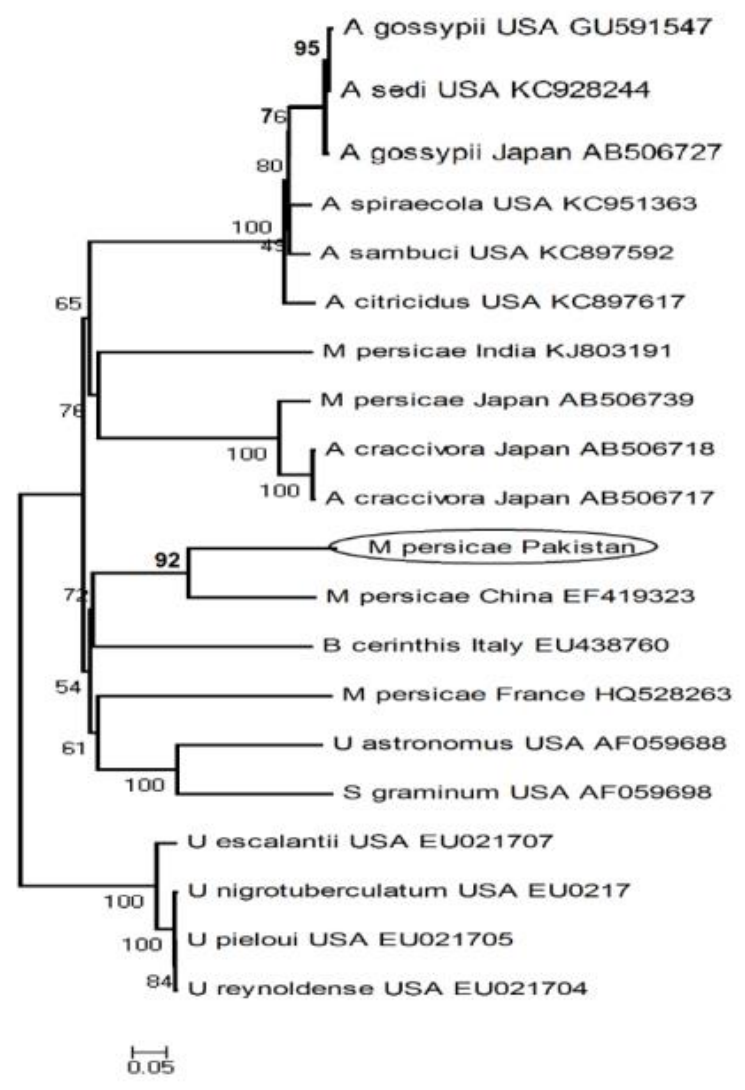

Figure-2b. Twenty sequences (Scientific name, country of origin and accession numbers) showing the evolutionary history of aphid populations, anecdotal using the $\mathrm{NJ}$ method, \% replicate saplings with associated taxa bunched together in the bootstrap way (500 replicates), sum of branch length $(\mathrm{SBL})=\mathbf{0 . 5 6 8 5 4 0 0 0}$.

The pairwise nucleotide distance datasets also indicated that two Pakistani sequences were quite divergent from the sequences of other countries (Table 2). Relatively high values were observed in comparisons with Japanese, Indian and France $M$. persicae populations whereas closely related trend was observed in Pakistani and Chinese M. persicae populations. 
Bilal Rasool et al.

Table-2. Computation of Nucleotide (Coding) Pairwise distance of Myzus persicae

\begin{tabular}{|c|c|c|c|c|c|c|c|c|c|c|c|c|}
\hline Sr. No. & & Pak1 & Pak2 & Ch1 & Ch2 & Ch3 & Ch4 & Jap1 & Jap2 & Jap3 & Ind1 & Ind2 \\
\hline 1 & Pak1 & & & & & & & & & & & \\
\hline 2 & Pak2 & 0.026 & & & & & & & & & & \\
\hline 3 & Ch1 & 0.022 & 0.016 & & & & & & & & & \\
\hline 4 & Ch2 & 0.022 & 0.016 & 0.000 & & & & & & & & \\
\hline 5 & Ch3 & 0.029 & 0.010 & 0.013 & 0.013 & & & & & & & \\
\hline 6 & Ch4 & 0.026 & 0.016 & 0.000 & 0.000 & 0.013 & & & & & & \\
\hline 7 & Jap1 & 0.083 & 0.098 & 0.096 & 0.096 & 0.089 & 0.096 & & & & & \\
\hline 8 & Jap2 & 2.054 & 2.005 & 2.005 & 2.007 & 2.010 & 2.005 & 2.263 & & & & \\
\hline 9 & Jap3 & 3.719 & 3.745 & 3.739 & 3.730 & 3.729 & 3.730 & 3.890 & 3.888 & & & \\
\hline 10 & Ind1 & 3.899 & 3.873 & 3.881 & 3.887 & 3.888 & 3.888 & 3.890 & 3.890 & 0.011 & & \\
\hline 11 & Ind2 & 3.909 & 3.911 & 3.911 & 3.919 & 3.918 & 3.919 & 3.982 & 3.994 & 0.036 & 0.033 & \\
\hline
\end{tabular}

Pak 1-2 (Pakistan), Ch 1-3 China), Jap 1, Jap 1-3 (Japan), Ind1-2 (India)

Table-3. Mitochondrial and Wolbachia samples in Myzus persicae from different localities

\begin{tabular}{|c|l|l|c|c|c|c|c|c|c|}
\hline $\begin{array}{c}\text { Sr. } \\
\text { No }\end{array}$ & Province & Localities & $\begin{array}{c}\text { Mt. PCR } \\
(\mathbf{n 0})\end{array}$ & $\begin{array}{c}\text { Positive mt. } \\
\text { samples }\end{array}$ & Mt. \% & $\begin{array}{c}\text { Total wsp } \\
\text { samples }\end{array}$ & $\begin{array}{c}\text { Positive wsp } \\
\text { samples }\end{array}$ & $\begin{array}{c}\text { \% wsp } \\
\text { \% }\end{array}$ & $\begin{array}{c}\text { Mean wsp } \\
\text { \% }\end{array}$ \\
\hline 1 & Punjab & Faisalabad & 10 & 9 & 90 & 15 & 2 & $13.33 \%$ \\
\hline 2 & Punjab & T.T. Singh & 10 & 8 & 80 & 15 & 5 & $33.33 \%$ \\
\hline 3 & Punjab & Samundri & 10 & 9 & 90 & 15 & 2 & $13.33 \%$ \\
\hline 4 & Punjab & Lahore & 10 & 9 & 90 & 15 & 0 & $0 \%$ \\
\hline 5 & Punjab & Kasur & 10 & 9 & 90 & 15 & 3 & $20 \%$ \\
\hline 6 & Punjab & Nankana & 10 & 9 & 90 & 15 & 2 & $13.33 \%$ \\
\hline 7 & Punjab & Multan & 10 & 8 & 80 & 15 & 3 & $20 \%$ \\
\hline 8 & Punjab & Khanewal & 10 & 8 & 80 & 15 & 3 & $20 \%$ \\
\hline 9 & Punjab & Lodhran & 10 & 9 & 90 & 15 & 2 & $13.33 \%$ & \\
\hline 10 & KPK & Peshawar & 10 & 8 & 80 & 15 & 1 & $6.66 \%$ \\
\hline 11 & KPK & Nowshera & 10 & 7 & 70 & 15 & 0 & $0 \%$ \\
\hline 12 & KPK & Charsadda & 10 & 7 & 70 & 15 & 2 & $13.33 \%$ & 6.66 \\
\hline 13 & Sindh & Hyderabad & 10 & 8 & 80 & 15 & 2 & $13.33 \%$ & \\
\hline 14 & Sindh & Dadu & 10 & 8 & 80 & 15 & & 1 \\
\hline 15 & Sindh & Jamshoro & 10 & 7 & 70 & 15 & & 1 & $6.66 \%$ \\
\hline & Total & & 150 & 123 & & 225 & 29 & $6.66 \%$ \\
\hline
\end{tabular}

Screening of Wolbachia in M. persicae populations with wsp gene

The hewed genomic DNA of 225 samples (15 per locality) was analyzed aimed at the screening of endosymbionts by wsp gene and samples of aphids were found infested. The infestation of these microbes in $M$. persicae population of Punjab was high as compared to KPK and Sindh population (Table 3) though the concreteness of Wolbachia endured quite low. The overall results showed that from 225 samples 29 were positive for Wolbachia infection with an average of $16.29 \%$ in Punjab, 6.66\% KPK and $8.88 \%$ in Sindh. The citywise high infection was found in T.T. Singh: $5 / 15=33.33 \%$, and lowest Lahore and Noshehra $M$. persicae populations whereas the of Wolbachia infection frequency in other cities was (Faisalabad: $2 / 15=(13.33 \%)$, Toba Tek Singh: $5 / 15=$
33.33\%, Samundri 2/15 (13.33\%), Lahore 0/15 (0\%), Kasur 3/15 (20\%), Nankana 2/15 (13.33\%), Multan 3/15 (20\%) Khanewal 3/15 (20\%), Lodhran 2/15 (13.33\%) Hyderabad: 2/15 (13.33\%) Dadu 1/15 (6.66\%), Jamshoro 1/15 (6.66\%), Peshawar: 1/15 (6.66\%), Nowshera $0 / 15(0 \%)$ and Charsada 2/15 $(13.33 \%)$. These results were also quantified with the real-time qPCR analysis and confirmed the results of the conventional PCR datasets.

\section{Discussion}

During this study, three different parameters including host preference of $M$. persicae were investigated. Aphid prevalence was variegated with diverse epochs may be due to ecological aspects (Blackman and Eastop, 2018). Rearing of aphid species was carried 
out on natural as well as artificial diets to have an overview of the influences of both diets on the population dynamics. Maximum population growth was professed on a natural diet eggplant, cabbage, lettuce and broccoli which provide additional information related to habitat and nutritional requirements of this pest species (Weber, 1985). Intrerpecific plants and diets variability in host plant adaptation of $M$. persicae may be significant from an epidemiological perceptive and host plant selection process. The present findings regarding host preference and aphid-plant interactions may help to provide insights into such interactions which will have broad implications at different direct and indirect stages including devising strategies of novel aphid management. In the greenhouse conditions during June and July temperature was high, so the population of aphids exhibited declining trend (Davis et al., 2006) whereas during August humidity increased and temperature lowered as compared to June and July, therefore the population of $M$. persicae also increased. Temperature and humidity were maintained in lab conditions so no much population fluctuation of $M$. persicae was observed during these experiments. The overall population datasets favored the results regarding the natural diet which indicates better nutritional values of natural diets. Based on these datasets the nutritional values of the artificial diets may be more improved in future experiments for further standardization.

$M$. persicae samples were identified through barcoding methods using mitochondrial cytochrome oxidase unit I and phylogenetic analysis showed that $M$. persicae populations were quite diverse subsequently the populations from different countries though the resemblance was found with the aphid sequences from China. The genetic variation in insect's population of a species influenced by numerous reasons for instance climate change, environmental factors and natural barriers (Fairley et al., 2000; Pauls et al., 2013) and the environmental factors of these geographical arena is quite similar, therefore these factors might be posiible reason of genetic variations.

During these studies, molecular marker like COI was used for phylogenetic studies which were considered as a valuable tool to study the phylogenetic and levels of a hierarchy of various organisms as well as most of the insects and anticipated using a potential insect sympathy (Patwardhan et al., 2014). Cytochrome Oxidase I based DNA barcoding has been proved quite helpful in the identification of many cryptic and sibling species as well (Bucklin et al., 2007; Pfenninger and Schwenk, 2007). Our results showed a good performance of the DNA barcode for identification of $M$. persicae populations in Pakistan just similar to the other insect species (Rasool et al., 2019).

We surveyed and found $w s p$ positive amplification for the first time in $M$. persicae population of Pakistan. Wolbachia was not identified in any sorts' veteran of the genera Uroleucon, Myzus, Capitophorus and Sitobion though endosymbiosis was described in earlier appraisal (Wang et al., 2014). The findings accomplished as the present study exhibited the Wolbachia infection are comparatively high in Punjab populations as compared to the populations of Sindh and KPK, while the almost high positive trend is found in mitochondrial phylogeny further Wolbachia and mitochondria have similar evolutionary interests to disperse from mother to offspring this can be assumed that high Wolbachia density and strain diversity is present in the samples (Chen et al., 2019). Mitochondrial DNA and Wolbachia have similarities in dispersal patterns that explain role in speciation and phylogenetic relationship in many species including aphids (Augustinos et al., 2011). Wolbachia infection was found comparatively high in tropical to subtropical areas (Morrow et al., 2015) and the overall climate of our selected areas remained subtropical to temperate, therefore Wolbachia infection rate was different in our study areas.

Wolbachia-induced cytoplasmic incompatibility can be utilized for the control of agricultural insects and disease vectors through the Incompatible Insect Technique (IIT) as well as lethal wsp strains pact the prospective control for vector species by amending their populace age edifice (Dutra et al., 2015). Molecular identification of $M$. persicae provides a promising and valid tool for the identification of aphid species and the development of phylogenetic relationships among species (Rasool et al., 2019). Environment-friendly tools as the possible application through biological control programs to reduce the pest status and enhance the productivity of the agricultural crop (Rasool et al., 2017) along with the increased genetic resistance and concocting strategy for reducing the noxious effects of chemical control of the aphid control programs is essential. The investigation of multiple infection status and new wsp strains diversifications will open new horizons for aphid pest management. 


\section{Conclusion}

Rearing of Myzus persicae, economically imperious crop pest exhibited maximum population growth on natural diets in greenhouse conditions as compared to artificial diets in lab conditions. Myzus persicae displayed the highest preference for cabbage and eggplant among ten different host plants in greenhouse conditions. Mitochondrial COI gene exhibited maximum positive amplification in almost all population of $M$. persicae. A comparison of mitochondrial sequences exhibited genetic variability. Screening of Wolbachia revealed positive amplification in $M$. persicae populations and maximum infection rate persisted in Punjab $16.29 \%$. The endosymbiotic Wolbachia may be ascribed as a possible means for aphid pest management programs.

\section{Acknowledgement}

The authors are grateful to Rizwan Munir, Department of Statistics, Government College University, Faisalabad, Pakistan for his valuable statistical assistance.

\section{Disclaimer: None. \\ Conflict of Interest: None. Source of Funding: None.}

\section{References}

Altschul SF, Madden TL, Schaffer AA, Zhang J, Zhang Z, Miller W and Lipman DJ, 1997. Gapped BLAST and PSI-BLAST: a new generation of protein database search programs. Nucl. Acid. Res. 25: 3389-3402.

Augustinos AA, Santosgarcia D, Dionyssopoulou E, Moreira M, Papapanagiotou A, Scarvelakis M, Doudoumis V, Ramos S, Aguiar AF, Borges PA and Khadem M, 2011. Detection and characterization of Wolbachia infections in natural populations of aphids: is the hidden diversity fully unraveled? PLOS One. 12: e28695.

Bass C, Puinean AM, Zimmer CT, Denholm I, Field LM, Foster SP, Gutbrod O, Nauen R, Slater R, and Williamson MS, 2014. The evolution of insecticide resistance in the peach potato aphid, Myzus persicae. Insect Biochem. Mol. Biol. 51: 41-51.
Blackman RL and Eastop VF, 2018. Aphids on the World's Plants. Available from: http://www.aphidsonworldsplant.info.

Braig HR, Zhou W, Dobson SL and O’Neill SL, 1998. Cloning and Characterization of a Gene Encoding the Major Surface Protein of the Bacterial Endosymbiont Wolbachia pipientis. J. Bacteriol. 9: 2373-2378.

Brault V, Tanguy S, Reinbold C, Le Trionnaire G, Arneodo J, Jaubert-Possamai S, Guernec G and Tagu D, 2010. Transcriptomic analysis of intestinal genes following the acquisition of pea enation mosaic virus by the pea aphid Acyrthosiphon pisum. J. Gen.Virol. 91(3): 802-8.

Bucklin A, Wiebe PH, Smolenack SB, Copley NJ, Beaudet JG, Bonner KG, Färber-Lorda $\mathrm{J}$ and Pierson JJ, 2007. DNA barcodes for species identification of euphausiids (Euphausiacea, Crustacea). J. Plankton Res. 29(6): 483-493.

Caterino MS, Cho S and Sperling FAH, 2000. The current state of insect molecular systematics: a thriving Tower of Babel. Annu. Rev. Entomol. 45: $1-54$

Chen R, Su X, Chen J, Jiang L and Qiao GX, 2019. Wolbachia Infection in Two Species: Novel Views on the Colonization Ability of Wolbachia in Aphids. Environ. Entomol. 48(6): 1388-1393. https://doi.org/10.1093/ee/nvz122

Dadd RH, Krieger DL and Mittler TE, 1967. Studies on the artificial feeding of the aphid Myzus persicae (Sulzer). Requirements for water-soluble vitamins and ascorbic acid. J. Insect. Physiol. 13(2): 249-72.

Davis JA, Radcliffe EB and Ragsdale DW, 2006. Effects of high and fluctuating temperatures on Myzus persicae (Hemiptera: Aphididae). Environ. Entomol. 35(6): 1461-1468.

Dutra HL, Dossantos LM, Caragata EP, Silva JB, Villela DA, Maciel-de-Freitas R and Moreira LA, 2015. From lab to the field: the influence of urban landscapes on the invasive potential of Wolbachia in Brazilian Aedes aegypti mosquitoes. PLOS Negl. Trop. Dis. 9(4): e0003689.

Dyer KA and Jaenike J, 2004. Evolutionarily stable infection by a male-killing endosymbiont in Drosophila innubila: molecular evidence from the host and parasite genomes. Genetics. 168(3): 1443-1455.

Fairley TL, Renaud TM and Conn JE, 2000. Effects of local geographic barriers and latitude on population structure in Anopheles punctipennis 
(Diptera: Culicidae). J. Med. Entomol. 5: 754-60.

Ferrari J, Via S and Godfray HC, 2008. Population differentiation and genetic variation in performance on eight hosts in the pea aphid complex. Evolution: Int. J. Organ. Evol. 62(10): 2508-2524.

Gómez-Valero L, Soriano-Navarro M, Pérez-Brocal V, Heddi A, Moya A, García-Verdugo JM and Latorre A, 2004. Coexistence of Wolbachia with Buchnera aphidicola and a secondary symbiont in the aphid Cinara cedri. J. Bacteriol. 186(19): 6626-6633.

Hamed S, 1983. Natural balance of graminicolous aphid in Pakistan, Survey of populations. Agron. 3: 665-673.

Hebert PDN, Cywinska A, Ball SL and de-Waard JR, 2002. Biological identifications through DNA barcodes. Proc. Royal Soc. B. 270: 313-321.

Hilgenboecker K, Hammerstein P, Schlattmann P, Telschow A and Werren JH, 2008. How many species are infected with Wolbachia? a statistical analysis of current data. FEMS Microb. Lett. 281(2): 215-20.

Jeyaprakash A and Hoy MA, 2000. Long PCR improves Wolbachia DNA amplification: wsp sequences found in $76 \%$ of sixty-three arthropod species. Insect. Mol. Biol. 9(4): 393-405.

Kumar S, Tamura K, Jakobsen IB and Nei M, 2001. MEGA2: Molecular evolutionary genetics analysis software. Bioinformatics. 17(12): 12441245.

Loxdale HD, Hardie JI, Halbert SU, Foottit RO, Kidd NA and Carter CI, 1993. The relative importance of the short-and long-range movement of flying aphids. Biol. Rev. 68(2): 291-311.

Loxdale HD and Lushai G, 2007. Population genetic issues: the unfolding story using molecular markers. Aphids as Crop Pests. CABI, Wallingford, UK. pp. 31-67.

Loxdale HD, Edwards O, Tagu D and Vorburger C, 2017. Aphid genomics and its contribution to understanding aphids as crop pests. Aphids as Crop Pests CABI, Wallingford, UK.

Morrow JL, Frommer M, Royer JE, Shearman DC and Riegler M, 2015. Wolbachia pseudogenes and low prevalence infections in tropical but not temperate Australian tephritid fruit flies: manifestations of lateral gene transfer and endosymbiont spillover? BMC Evol. Biol. 15: 202.
Nirgianaki A, Banks GK, Frohlich DR, Veneti Z, Braig HR, Miller TA, Bedford ID, Markham PG, Savakis C and Bourtzis K, 2003. Wolbachia infections of the whitefly Bemisia tabaci. Curr. Microbiol. 47(2): 0093-0101.

Patwardhan A, Ray S and Roy A, 2014. Molecular markers in the phylogenetic studies-a review. J. Phylog. Evol. Biol. 2(2): 1000131.

Pauls SU, Nowak C, Bálint $\mathrm{M}$ and Pfenninger M, 2013. The impact of global climate change on genetic diversity within populations and species. Mol. Ecol. 22: 925-946.

Pfenninger M and Schwenk K, 2007. Cryptic animal species are homogeneously distributed among taxa and bio geographical regions. BMC Evol. Biol. 7(1): 121.

Poinsot D, Charlat S and Mercot H, 2003. On the mechanism of Wolbachia-induced cytoplasmic incompatibility: confronting the models with the facts. Bioessays. 25(3): 259-265.

Rasool B, Khalid M, Rasul A, Mansoor H, Jabeen F, Rasool A and Munir R, 2019. Red flour beetle Tribolium castaneum (Tenebrionidae, Coleoptera): Population dynamics, screening of Wolbachia in different regions and cereal foods of Pakistan. Pak. Entmol. 41(1): 13-20.

Rasool B, Rafique M, Asrar M, Rasool R, Adeel M, Rasul A and Jabeen F, 2017. Host preference of Bactrocera flies species (Diptera: Tephritidae) and parasitism potential of Dirhinus giffardii and Pachycropoideus vindemmiae under laboratory conditions. Pak. Entmol. 39(1): 17-21.

Simon C, Frati F, Beckenbach A, Crespi B, Liu H and Flook P, 1994. Evolution, weighting, and phylogenetic utility of mitochondrial gene sequences and a compilation of conserved polymerase chain reaction primers. Ann. Entomol. Soc. Am. 87(6): 651-701.

Stouthamer R, Breeuwer JA and Hurst GD, 1999. Wolbachia pipientis: microbial manipulator of arthropod reproduction. Annu. Rev. Microbiol. 53(1): 71-102.

Thompson JD, Higgins DG and Gibson TJ, 1994. CLUSTAL $\mathrm{W}$ : improving the sensitivity of progressive multiple sequence alignment through sequence weighting, position-specific gap penalties and weight matrix choice. Nucl. Acid. Res. 22 (22):4673-80.

Van Emden HF, 2017. Integrated pest management of aphids and introduction to IPM case studies. In: Van Emden, H. F. and Harrington, R. (eds.) 
Aphids as Crop Pests, $2^{\text {nd }}$ edition. CABI, Wallingford, UK. pp. 533-544.

Vandekerckhove T, Watteyne S, Bonne W, Vanacker D, Devaere S, Rumes B, Maelfait JP, Gillis M, Swings J, Braig HR and Mertens J, 2003. Evolutionary trends in feminization and intersexuality in woodlice (Crustacea, Isopoda) infected with Wolbachia pipientis (alphaproteobacteria). Belg. J. Zool. 133(1): 61-69.

Wang Z, Su XM, Wen J, Jiang LY and Qiao GX, 2014. Widespread infection and diverse infection patterns of Wolbachia in Chinese aphids. Insect. Sci. 21(3): 313-25.

Weber G, 1985. Genetic variability in host plant adaptation of the green peach aphid, Myzus persicae. Entoml. Exp. Appl. 38(1): 49-56.

Werren JH, Baldo L, and Clark ME, 2008. Wolbachia: master manipulators of invertebrate biology. Nature Rev. Microbiol. 6(10): 741-751.

Yang C, Pan H, Liu Y and Zhou X, 2014. Selection of Reference Genes for Expression Analysis Using
Quantitative Real-Time PCR in the Pea Aphid, Acyrthosiphon pisum (Harris) (Hemiptera, Aphidiae). PLOS One 9(11): e110454. https://doi.org/10.1371/journal.pone.01 10454

\section{Contribution of Authors}

Rasool B: Conceived idea, designed research methodology, literature review, data collection, statistical analysis and manuscript writing Nabi Z: Data collection and analysis Bodlah MA: Literature review and article write up Afzal N: Data collection and analysis Samiullah K: Data interpretation Rasool A: Data interpretation Rasool R: Data collection and analysis 